\title{
Gambaran Kunjungan Pasien Rawat Jalan Endokrinologi Anak dan Remaja FK USU / RS. H. Adam Malik Medan, Tahun 2000-2004
}

\author{
Melda Deliana, Hakimi, Siregar CD
}

Latar belakang. Masyarakat banyak yang tidak mengetahui bahwa kelainan endokrin pada anak membutuhkan penanganan yang khusus dari ahli endokrinologi anak.

Tujuan penelitian. Penelitian ini bertujuan untuk mengetahui gambaran kunjungan pasien endokrinologi anak dan remaja di RS H.Adam Malik Medan tahun 2000-2004. Metoda. Penelitian ini merupakan studi deskriptif retrospektif. Data diperoleh dari catatan rekam medik pasien yang berkunjung ke Poliklinik Endokrinologi Anak dan Remaja FKUSU/RS. H. Adam Malik Medan dalam kurun waktu Januari 2000-Desember 2004.

Hasil. Terdapat 93 pasien yang berkunjung ke Poliklinik Endokrinologi Anak dan Remaja, 33 anak perempuan (35\%) dan 60 anak laki-laki(65\%). Sebaran umur pada saat datang pertama kali adalah 33 anak (35\%) berusia 0-5 tahun, 25 anak (27\%) berusia $>$ 5-10 tahun, 25 anak (27) \% > 10-15 tahun, dan 10 anak (11\%) berusia >15 tahun. Keluhan utama yang paling sering muncul pada saat pasien datang berobat pertama kali adalah alat kelamin laki-laki kecil 15 kasus (16\%) dan buah zakar tidak turun 15 kasus (16\%), keluhan anak pendek 13 kasus (14\%), benjolan di leher 12 kasus (13\%). Diagnosis yang dijumpai adalah kriptorkismus $(20 \%)$, mikropenis $(16 \%)$ dan hipotiroidisme kongenital (13\%). Status gizi berdasarkan NCHS WHO 2000 pada pasien yang berkunjung terutama gizi baik, terdapat pada 22 kasus $(23,6 \%)$.

Kesimpulan. Kasus terbanyak berkunjung ke Poliklinik Endokrinologi Anak dan Remaja adalah kriptorkismus (20\%), mikropenis (16\%) dan hipotiroidisme kongenital (13\%). Diduga masih banyak kasus endokrinologi anak dan remaja yang tidak ditangani oleh ahli endokrinologi anak secara komprehensif oleh karena kemungkinan banyak kasus yang tidak dirujuk.

Kata kunci: nefritis lupus, perdarahan intrakranial,hipertensi, vaskulitis

\footnotetext{
Alamat korespondensi:

Dr. Melda Deliana, SpA. Subbagian Endokrinologi. Bagian Ilmu Kesehatan Anak FK USU/RS HAM Jalan Bunga Lau No. 17 Medan 20136.

Telepon : (061) 8361721, Fax : (061) 8361721

E-mail : bikafkusu@telkom.net; kotak Pos 697 Medan - 20136
}

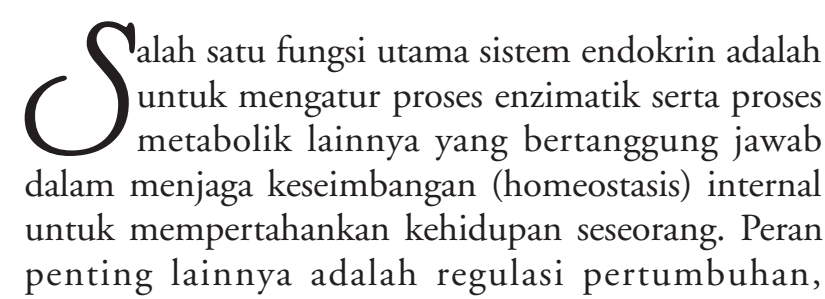


perkembangan pubertas dan reproduksi, produksi energi, pengaturan tekanan darah dan juga tingkah laku. ${ }^{1}$ Masyarakat banyak yang tidak mengetahui bahwa kelainan endokrin pada anak membutuhkan penanganan yang khusus dari ahli endokrinologi anak.

Penelitian ini bertujuan untuk mengetahui gambaran kunjungan pasien di bagian endokrinologi anak dan remaja di RS H.Adam Malik Medan tahun 2000-2004.

\section{Metoda}

Penelitian ini merupakan studi deskriptif retrospektif. Data diperoleh dari catatan rekam medik pasien yang berkunjung ke Poliklinik Endokrinologi Anak dan Remaja FKUSU/RS. H. Adam Malik Medan dalam kurun waktu Januari 2000-Desember 2004. Umur pasien dikelompokkan berdasarkan fase pertumbuhan yaitu pertumbuhan cepat I (0-5 tahun), lambat I (510 tahun), cepat II (10-15 tahun), lambat II (>15 tahun). Status antropometri ditetapkan berdasarkan NCHS WHO 2000 menurut berat badan terhadap umur, tinggi badan terhadap umur, dan berat badan terhadap tinggi badan. Dikatakan gizi buruk jika berat badan terhadap tinggi badan $<70 \%$, gizi kurang $<90$ $\%$, gizi baik 90\%-110\%, gizi lebih $>110 \%$, dan obesitas jika $>120 \%$. Perawakan pendek jika tinggi badan menurut umur $<$ persentil ke 3, normal jika tinggi badan menurut umur berada diantara persentil ke 3-97 dan perawakan tinggi jika tinggi badan menurut umur > persentil ke 97 .

Pencatatan keluhan utama saat datang berobat pertama kali berdasarkan keluhan utama yang langsung dikeluhkan oleh pasien ataupun dari aloanamnesis yang didapat dari orangtua (ayah atau ibu). Diagnosis pasien ditegakkan berdasarkan anamnesis, pemeriksaan fisis dan penunjang.

\section{Hasil}

Selama kurun waktu Januari 2000 hingga Desember 2004, terdapat 93 pasien yang berkunjung ke Poliklinik Endokrinologi Anak dan Remaja FKUSU/RS.Adam Malik Medan, terdiri dari 33 anak perempuan (35\%) dan 60 anak laki-laki (65\%). Sebaran umur pada saat datang pertama kali adalah 33 anak (35\%) berusia 0-5 tahun, 25 (27\%) berusia > 5-10 tahun, 25 (27) \% $>10-15$ tahun, dan sebanyak 10 (11\%) berusia $>15$ tahun. Keluhan utama yang paling sering muncul pada saat pasien datang berobat pertama kali adalah alat kelamin laki-laki kecil sebanyak 15 kasus (16\%) dan buah zakar tidak turun 15 kasus (16\%), diikuti perawakan pendek sebanyak 13 kasus (14\%), benjolan di leher 12 kasus (13\%). Keluhan utama lainnya tertera pada Tabel 1.

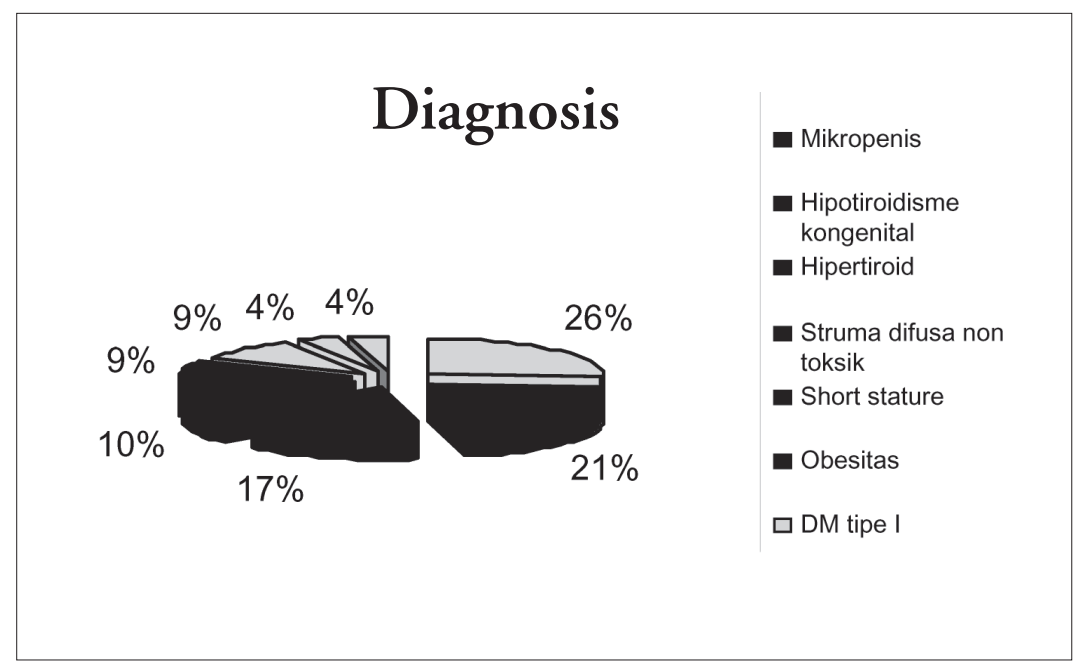

Gambar 1. Sebaran Diagnosis pasien endokrin yang berkunjung di Poliklinik Endokrinologi Anak dan Remaja FK USU / RS. H. Adam Malik Medan 
Sari Pediatri, Vol. 7, No. 4, Maret 2006

Tabel 1. Keluhan utama saat datang berobat pertama kali

\begin{tabular}{lcc}
\hline Keluhan utama & Jumlah & $\%$ \\
\hline Alat kemaluan kecil & 15 & 16 \\
Buah zakar tidak turun & 15 & 16 \\
Anak pendek & 13 & 14 \\
Benjolan di leher & 12 & 13 \\
Keringat berlebihan & 5 & 5 \\
Berat badan lebih & 2 & 2 \\
Badan lemas & 2 & 2 \\
Banyak makan & 2 & 2 \\
Sulit buang air besar & 2 & 2 \\
Kencing di bagian bawah kemaluan & 1 & 1 \\
Terlambat haid & 1 & 1 \\
Payudara tidak tumbuh & 1 & 1 \\
Tumbuh bulu di wajah & 1 & 1 \\
Kemaluan besar & 1 & 1 \\
Kemaluan biru & 1 & 1 \\
Payudara membesar sejak lahir & 1 & 1 \\
Benjolan di ketiak & 1 & 1 \\
Sering kencing & 1 & 1 \\
Seluruh tubuh gemetar & 1 & 1 \\
Ukuran anggota tubuh dengan tubuh tidak seimbang & 1 & 1 \\
Payudara sebelah kiri membesar & 1 & 1 \\
Belum bisa berjalan & 1 & 1 \\
Belum dijumpai tanda-tanda pubertas & 1 & 1 \\
Dijumpai tanda-tanda pubertas & 1 & 1 \\
Wajah mongoloid & 1 & 1 \\
Tidak tercatat & 9 & 9 \\
\hline Total & 93 & 100 \\
\hline
\end{tabular}

Pada Gambar 1 tertera diagnosis yang banyak dijumpai adalah kriptorkismus (20\%), mikropenis $(16 \%)$ dan hipotiroid kongenital (13\%), sedang obesitas dan diabetes melitus tipe 1 merupakan penyakit yang paling jarang.

Pada Gambar 2 terlihat status gizi berdasarkan NCHS WHO 2000 pada pasien yang berkunjung adalah gizi baik 22 kasus $(23,6 \%)$, diikuti oleh gizi kurang $17,2 \%$.

\section{Diskusi}

Kriptorkismus merupakan kelainan diferensiasi seksual yang paling sering pada anak laki-laki. ${ }^{1,2}$ Diantaranya 4,5\% ditemukan pada waktu lahir. ${ }^{2}$ Pada penelitian ini didapatkan bahwa diagnosis terbanyak adalah kriptorkismus yaitu 19 kasus (20\%), diikuti mikropenis 15 kasus (16\%). Hal ini sejalan dengan keluhan utama yang paling sering yaitu buah zakar tidak turun dan alat kelamin laki-laki kecil. Penelitian di empat taman kanak-kanak di Kotamadya Medan didapatkan 20 kasus (18,7\%) mikropenis, 77 kasus (72\%) penis kecil sedangkan ukuran penis normal 10 kasus $(9,4 \%){ }^{3}$ Tridjaja B dan Batubara JR, menemukan 23 kasus mikropenis di Poliklinik Endokrinologi Anak dan Remaja RSCM Jakarta pada tahun 1998-1999. ${ }^{4}$

Diagnosis tersering berikutnya adalah hipotiroidisme kongenital, yaitu sebanyak 12 kasus (13\%). Pada penelitian di RSCM Jakarta tahun 1992- 2002 didapatkan 30 kasus baru hipotiroidisme kongenital. ${ }^{5}$ Berdasarkan program skrining neonatal didapatkan 


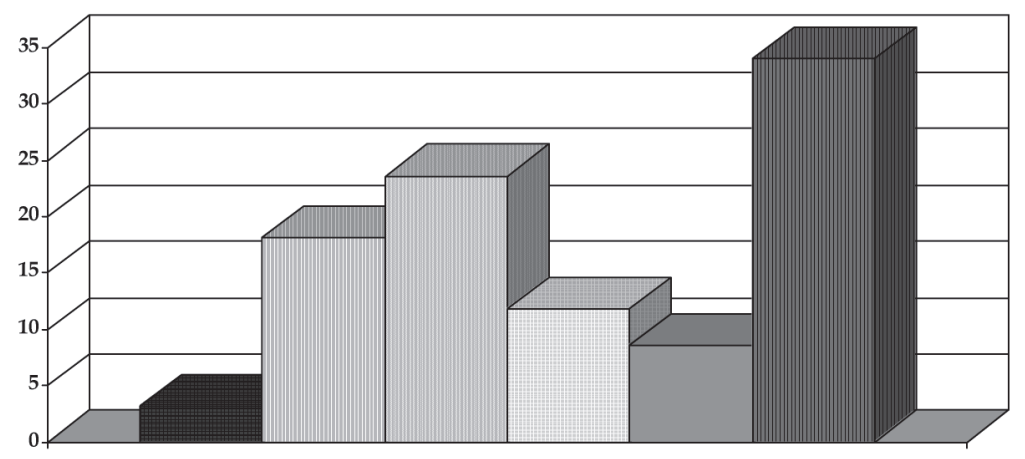

m gizi buruk $\square$ gizi kurang $\square$ gizi baik $\square$ gizi lebih $\square$ obesitas $\|$ data tdk lengkap

Gambar 2. Sebaran pasien endokrin berdasarkan status gizi

prevalensi hipotiroidisme kongenital sebesar 1: 4000 bayi di seluruh dunia. Sedangkan penelitian yang meneliti anak usia pra sekolah melaporkan hipotiroidisme kongenital dijumpai pada sekitar 0,08\% $(1: 1250)^{6}$ Hipotiroidisme kongenital merupakan kelainan endokrinologi terbanyak di Amerika Serikat setelah diabetes melitus, dengan prevalensi 18 kasus tiap 1000 orang populasi. ${ }^{7}$

Keluhan utama terbanyak setelah alat kelamin kecil dan buah zakar tidak turun adalah perawakan pendek, yaitu sebanyak 15 kasus (16\%). Dari data tinggi badan pasien yang berkunjung ke Bagian Endokrinologi anak \& remaja FK USU/RS H. Adam Malik Medan selama kurun waktu 5 tahun (2000-2004) didapati sebanyak 27 orang $(29 \%)$ memiliki tinggi badan < persentil ke3. Menjadi "pendek" menimbulkan berbagai masalah psikososial terutama pada masa remaja dan dewasa seperti kesulitan dalam hal pendidikan, pekerjaan dan hubungan antar sesama. ${ }^{8,9}$ Perawakan pendek merupakan alasan yang paling umum seorang anak dibawa ke dokter endokrinologi baik oleh orangtua sendiri atau rujukan dari dokter keluarga. ${ }^{10,11}$ Prevalensi perawakan pendek di Amerika Serikat adalah 2,5\% dari seluruh penduduk. ${ }^{12}$ Mayoritas anak dengan perawakan pendek tidak mengalami gangguan hormonal atau penyakit genetik. Data dari pasien yang dirujuk ke Bagian Endokrinologi Anak RS Northshore dari Januari 1973 hingga Juni 1991 didapatkan 63\% normal dan hanya $37 \%$ yang patologis. ${ }^{9}$ Suatu penelitian di Skotlandia didapatkan hanya $24 \%$ anak yang diteliti dengan penyebab organik, $8 \%$ mengalami defisiensi hormon pertumbuhan dengan prevalensi 1:4000 anak. ${ }^{13}$ Sedangkan penelitian di Iran mendapatkan dari 426 anak dengan perawakan pendek, $47 \%$ patologis sedangkan $53 \%$ merupakan variasi normal. ${ }^{14}$

Status gizi berdasarkan NCHS 2000 didapatkan 3 kasus $(3,2 \%)$ gizi buruk, 17 kasus $(18,1 \%)$ dengan gizi kurang, 22 kasus $(23,6 \%)$ gizi baik, 11 kasus $(11,8 \%)$ gizi lebih dan 8 kasus $(8,6 \%)$ dengan obesitas. Pada penelitian di RSCM Jakarta didapatkan 53,3\% pasien gizi buruk pada kasus hipotiroidisme kongenital. ${ }^{5}$ Pada suatu penelitian tentang obesitas pada anak yang dirujuk ke Bagian Endokrinologi Anak dan Remaja dijumpai mayoritas anak obesitas tersebut gizi lebih telah mulai terjadi di usia prasekolah. Tata laksana obesitas tidak efektif jika rujukan dilakukan setelah interval yang lama dari onset obesitas. ${ }^{15}$ Sedangkan penelitian pada dua SD swasta di kota Medan didapatkan 92,45\% anak perempuan menderita obesitas. ${ }^{16}$

\section{Kesimpulan}

Kasus yang paling banyak dijumpai adalah kriptorkismus (20\%), mikropenis (16\%) dan hipotiroidisme kongenital (13\%). Masih banyak kasus endokrinologi anak dan remaja yang tidak ditangani oleh ahli endokrinologi anak secara komprehensif oleh karena kemungkinan banyak kasus yang tidak dirujuk.

\section{Ucapan Terimakasih}

Ucapan terima kasih untuk dr. Nancy Ervani dan dr. Rina A.C Saragih atas bantuannya dalam mengumpulkan data. 


\section{Daftar Pustaka}

1. Kappy MS, Steelman JW, Trawers SH, eiler PS. Endocrine disorders. Dalam: Hay WW, Hayward AR, Levin MJ, Soundheimer JM, penyunting. Current pediatric diagnosis \& treatment. Edisi ke-16. New York: Lange,2003. h. 937-85

2. Elder JS. Urologic disorders in infants and children. Dalam: Behrman RE, Kliegman RM, Jenson HB, penyunting. Nelson textbook of pediatrics. Edisi ke 17. Philadelphia: Saunders,2004. h. 1817-8

3. Hakimi, Siregar CD, Melda Deliana. Prevalensi mikropenis pada murid taman kanak-kanak. Sari Pediatri 2004; 6:115-8.

4. Tridjaya B, Batubara JRL, Pulungan A. Pengobatan testosteron pada mikropenis. Sari Pediatri 2002; 4:63-6

5. Melda Deliana, Batubara JR, Tridjaja B, Pulungan AB. Hipotiroidisme congenital di Bagian Ilmu Kesehatan Anak RS Ciptomangunkusumo Jakarta, tahun $1992-$ 2002. Sari Pediatri 2003; 5:79-84.

6. Franchi LS. Disorders of the thyroid gland. Dalam: Behrman RE, Kliegman RM, Jenson HB, penyunting. Nelson textbook of pediatrics. Edisi ke 17. Philadelphia: Saunders,2004. h. 1870-8.

7. Hueston WJ. Treatment of hypothyroidism. Am Fam Physician 2001; 64:1717-24.

8. Grinberg A, Leon DD. Disorders of growth. Dalam:
Moshang T, penyunting. Pediatric endocrinology the requisites in pediatrics. Edisi ke-1. St.Louis: Mosby, 2005. h. 127-62.

9. Lifshitz F, Cervantes CD. Short stature. Dalam: Lifshitz F, penyunting. Pediatric endocrinology. Edisi ke-3. New York: Marcel Dekker Inc, 1996. h. 1-15.

10. Randeva HS, Bouloux PM. Evaluation of short stature. Diambil dari: http//www.studentbmj.com/issues/00/05/education/143.php

11. Styne DM. Pediatric endocrinology. Philadelphia, 2004. h. 44-82.

12. Ferry RJ. Short stature. Diambil dari: http//www. emedicine.com/ped/topic 2087.htm

13. Hintz RL. Management of disorders of size. Dalam: Brook CGD, Hindmarsh PC, penyunting. Clinical pediatric endocrinology. Edisi ke-4. London: Blackwell Science Ltd, 2002. h. 126-30.

14. Moayeri H, Aghighi Y. A prospective study of etiology of short stature in 426 short children and adolescents. Arch Iranian Med 2004; 7:23-7.

15. Quantrin T, Liu E, Shaw N, Shine B, Chiang E. Obese children who are referred to the pediatric endocrinologist: characteristics and outcome. Pediatrics 2005; 115:348-51

16. Evalina R, Hakimi, Siregar CD.Hubungan obesitas dengan menars pada dua SD swasta kota Medan. Tesis. Medan: Bagian Ilmu Kesehatan Anak FK USU,2002 